\title{
Influence of Contact Points on the Performance of Caries Detection Methods in Approximal Surfaces of Primary Molars: An in vivo Study
}

\author{
Apoena A. Ribeiro ${ }^{a, b}$ Flávia Purger ${ }^{c}$ Jonas A. Rodrigues ${ }^{e}$ \\ Patrícia R.A. Oliveira ${ }^{a}$ Adrian Lussi ${ }^{\text {h }}$ Antonio Henrique Monteiro ${ }^{d}$ \\ Haimon D.L. Alves ${ }^{f}$ Joaquim T. Assis ${ }^{g}$ Adalberto B. Vasconcellos ${ }^{a}$ \\ ${ }^{a}$ Faculty of Dentistry and ${ }^{b}$ LabPECMA (Laboratory of Clinical, Microbiological and Chemical Research), Fluminense \\ Federal University, Nova Friburgo, ${ }^{c}$ Faculty of Dentistry and ${ }^{d}$ Faculty of Engineering, Fluminense Federal University, \\ Niterói, ${ }^{e}$ Faculty of Dentistry, Federal University of Rio Grande do Sul, Porto Alegre, ${ }^{f}$ Nuclear Instrumentation Lab, \\ Nuclear Engineering Program - COPPE, Federal University of Rio de Janeiro, and 9Polytechnical Institute of Rio de \\ Janeiro, State University of Rio de Janeiro, Rio de Janeiro, Brazil; h' School of Dental Medicine, University of Bern, \\ Bern, Switzerland
}

\section{Key Words}

Caries detection · Laser fluorescence $\cdot$ Noncavitated lesions

\begin{abstract}
This in vivo study aimed to evaluate the influence of contact points on the approximal caries detection in primary molars, by comparing the performance of the DIAGNOdent pen and visual-tactile examination after tooth separation to bitewing radiography (BW). A total of 112 children were examined and 33 children were selected. In three periods ( $a, b$, and c), 209 approximal surfaces were examined: (a) examiner 1 performed visual-tactile examination using the Nyvad criteria (EX1); examiner 2 used DIAGNOdent pen (LF1) and took BW; (b) 1 week later, after tooth separation, examiner 1 performed the second visual-tactile examination (EX2) and examiner 2 used DIAGNOdent again (LF2); (c) after tooth exfoliation, surfaces were directly examined using DIAGNOdent (LF3). Teeth were examined by computed microtomography as a reference standard. Analyses were based on diagnostic thresholds: D1: $\mathrm{D}_{0}=$ health, $\mathrm{D}_{1}-\mathrm{D}_{4}=$ disease; $\mathrm{D} 2: \mathrm{D}_{0}, \mathrm{D}_{1}=$ health, $D_{2}-D_{4}=$ disease; D3: $D_{0}-D_{2}=$ health, $D_{3}, D_{4}=$ disease. At $D 1$, the highest sensitivity/specificity were observed for
\end{abstract}

EX1 (1.00)/LF3 (0.68), respectively. At D2, the highest sensitivity/specificity were observed for LF3 (0.69)/BW (1.00), respectively. At D3, the highest sensitivity/specificity were observed for LF3 (0.78)/EX1, EX2 and BW (1.00). EX1 showed higher accuracy values than LF1, and EX2 showed similar values to LF2. We concluded that the visual-tactile examination showed better results in detecting sound surfaces and approximal caries lesions without tooth separation. However, the effectiveness of approximal caries lesion detection of both methods was increased by the absence of contact points. Therefore, regardless of the method of detection, orthodontic separating elastics should be used as a complementary tool for the diagnosis of approximal noncavitated lesions in primary molars.

๑ 2015 S. Karger AG, Basel

The presence of approximal contact makes the detection of initial lesions on the proximal surfaces difficult [Ekstrand, 2000]. Thus, for a more effective diagnosis, a visual exam associated with radiographic (bitewing) exams has traditionally been used [Wenzel, 2000; Sanden et al., 2003; Lussi et al., 2006]. Radiography, however, pre-

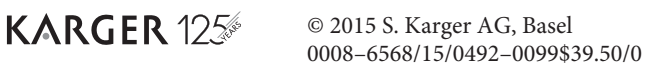

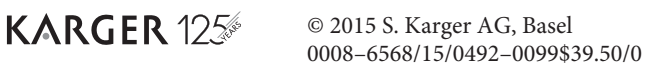

E-Mail karger@karger.com

www.karger.com/cre
}

Apoena de Aguiar Ribeiro

Rua Doutor Sylvio Henrique Braune 22

Centro

Nova Friburgo, RJ 28625-650 (Brazil)

E-Mail apoenaribeiro@vm.uff.br 
sents low sensitivity and high interexaminer variability [Hintze and Wenzel, 1994; Ricketts et al., 1997; Wenzel, 2004; Hala et al., 2006].

In order to find more sensitive and specific methods, a laser fluorescence device, named DIAGNOdent, was developed for the detection of carious lesions. This device measures the severity of carious lesions by providing numerical values, which, according to the manufacturer, establish a direct relationship to the lesion depth. In the examination of proximal surfaces, however, the device presented limited value, since its tips were incapable of penetrating the interproximal space [Lussi et al., 2006]. Another device, designated DIAGNOdent 2190 or the DIAGNOdent pen, was launched on the market in 2005, but few studies have been conducted up to the writing of this article, with the purpose of evaluating its accuracy in vitro [Lussi et al., 2006; Lussi and Hellwig, 2006; Aljehani et al., 2007; Kühnisch et al., 2007a, b; Rodrigues et al., 2008], all being conducted strictly in permanent teeth. In vivo studies conducted on proximal surfaces in primary teeth used the visual clinical examination as a standard method [Novaes et al., 2009, 2010, 2012]. Histological validation was done only in the in vitro study by Braga et al. [2009].

As regards the examination of the approximal surfaces of primary teeth, the broader area of proximal contact makes it difficult to perform an effective diagnosis. In view of this problem, many lesions remain undetected and their progression to advanced stages of the disease occurs more rapidly when compared to permanent teeth. This could be explained by some of the characteristics of primary teeth, such as the thinner enamel and dentin layers [Mortimer, 1970], lower degree of mineralization [Wilson and Beynon, 1989], wider dentinal tubules in comparison with permanent teeth [Murray and Majid, 1978], and wide area of contact allowing greater biofilm accumulation [Pitts and Rimmer, 1992]. Therefore, at present, there are increasing endeavors to detect lesions while they are still in their initial white spot stage, when mineral loss has not yet caused surface discontinuity and loss of substance on the surface in question. The importance of an early lesion detection is justified by the possibility of treating these lesions by noninvasive methods, sparing the child the painful experience and emotional tension, in addition to increasing the chances of permanence of the primary teeth until the time of their normal exfoliation. Based on the foregoing, the aim of the present study was to evaluate the influence of approximal contact points by comparing, for the first time in the literature, the performance of the DIAGNOdent pen and visual-tac- tile examination after tooth separation to bitewing radiography (BW), in the detection of incipient approximal caries lesions in primary molars in vivo, using the computed microtomography $(\mu \mathrm{CT})$ as a reference standard.

\section{Subjects and Methods}

\section{Study Design and Sample Selection}

The experimental protocol used in the present clinical study was approved by the Research Ethics Committee of the School of Medicine, Fluminense Federal University (Niterói, R.J., Brazil; document CEP CMM/HUAP No. 310/09). All children examined were volunteers and permission was obtained from their guardians for participation in the research, by means of signature on a Term of Free and Informed Consent. For the use of exfoliated primary molars, a Donation Term was also signed by the guardians of the children.

The study was designed as a pragmatic trial. A total of 112 children were examined. The choice of the participating schoolchildren was random, both genders and in the age range of 8-12 years old. The final sample consisted of 209 approximal surfaces of 137 maxillary and mandibular primary molars, selected from 33 children of two public schools in the Municipality of Nova Friburgo, R.J., Brazil. The selected children presented a minimum of one tooth in an advanced stage of exfoliation (more than two thirds of the root resorbed, verified by BW), without mobility higher than score 1 of the Miller classification (the first distinguishable sign of movement greater than normal). All the surfaces included were in contact with the adjacent tooth. Surfaces were excluded from the selection if they presented proximal restorations, cavitated lesions with absence of marginal crest, hypoplasia or demarcated opacity, absence of the adjacent tooth or scores 2 or 3 of the Miller classification [1938].

\section{Clinical Exams}

This study was divided into three periods (fig. 1). The first appointment consisted of visual-tactile (EX1), BW and DIAGNOdent pen (LF1) examinations, all performed by independent examiners at the School of Dentistry, Nova Friburgo, Fluminense Federal University, to avoid possible interference in the diagnosis.

At the first appointment, after cleaning with dental floss, the surfaces were examined using a mirror and exploratory probe, under proper lighting, drying with compressed air and relative isolation with cotton rolls, to perform the visual-tactile examination (EX1). This exam was performed by a previously calibrated examiner (A.A.R., examiner 1), in accordance with the criteria of $\mathrm{Nyvad}$ et al. $[1999,2009]$ (table 1); $\kappa$ value for the Nyvad criteria was 0.90 . Then, at the same appointment, DIAGNOdent pen (KaVo, Biberach, Germany) examination (LF1) was performed by a previously calibrated examiner 2 (F.P.), blinded regarding the visual-tactile examination. Previous training sessions to perform this examination took place in the Cariology Laboratory, Department of Preventive, Restorative and Pediatric Dentistry, University of Bern, for 10 days. The calculated $\kappa$ obtained after training was 0.94 . The type 1 tip (indicated for approximal surfaces) was used to perform the measurements. Before and during the exams, the device was calibrated and used according to the manufacturer's instructions, 
Fig. 1. Study flowchart describing the sequence of examinations performed in the study.

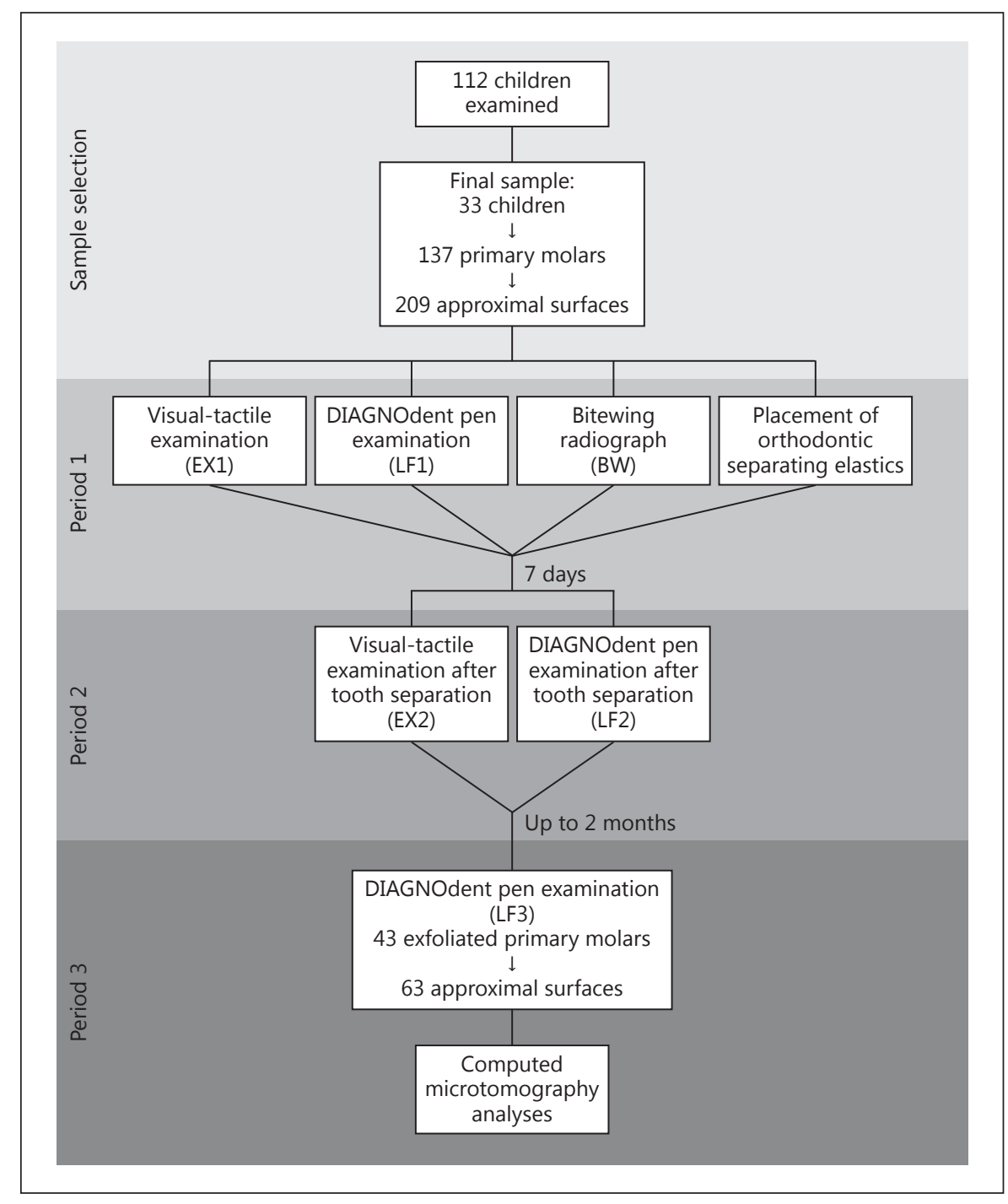

after isolation with cotton rolls and drying the teeth for $5 \mathrm{~s}$ with compressed air. The tip was introduced below the proximal contact area, from both buccal and lingual sides, in order to perform the exams. Therefore, for each surface, two values were obtained and the highest was recorded (LF1). After the measurements, the lesions were classified according to the cutoff points suggested by Lussi et al. [2006], according to table 2.

Then, at the same appointment, BW were obtained, using an interproximal radiographic positioner (CONE, Maquira, Maringá, Brazil), with an exposure time of $0.3 \mathrm{~s}$, using an X-ray device (Heliodent 70, model 0876805 D100B, Siemens, Rio de Janeiro, Brazil) set to $70 \mathrm{kV}$ and $8 \mathrm{~mA}$. Up to $2 \mathrm{BW}$ were taken of each child, right and/or left, in order to include all of the selected proximal surfaces in the study. The radiographs were processed in accordance with the manufacturer instructions (Kodak E-speed, Kodak, USA). The radiographs were numbered and mounted on a mask for analysis. After observing the radiographs in a backlight, the surfaces were classified (P.R.A.O., examiner 3) according to the criteria of Kidd et al. [2005] and Mejàre et al. [1999] (table 3).
After this examination, orthodontic separating elastics were placed between the selected surfaces, which remained in place for 7 days. At the second appointment, after 7 days of elastics placement, they were removed, the surfaces were cleaned with dental floss, then clinical examinations (EX2) and measurements with DIAGNOdent pen (LF2) were performed right after tooth separation as described above.

At the third appointment, exams were performed in 43 exfoliated teeth (63 of the 209 surfaces), since many teeth did not exfoliate within the time established in the study schedule, whereas other exfoliated teeth were lost by the participating children. The maximum time elapsed between the last exam and exfoliation was 2 months. The exfoliated teeth were washed in distilled water and afterwards frozen in flasks with a lid, containing a small piece of sponge dampened with some drops of distilled water so that there would be no change in fluorescence [Francescut et al., 2006; Lussi et al., 2006]. Before the measurements were taken with the device, the samples were defrosted for $3 \mathrm{~h}$, and still kept in the humid and sealed environment. DIAGNOdent pen examination (LF3) was 
Table 1. Index proposed by Nyvad et al. [1999] for caries diagnosis, complemented by Nyvad et al. [2009]

\begin{tabular}{lll}
\hline Score & Category & Criterion \\
\hline 0 & Healthy & Translucence and normal texture of enamel. \\
\hline 1 & $\begin{array}{l}\text { Active caries, intact } \\
\text { surface }\end{array}$ & $\begin{array}{l}\text { Enamel surface whitened/yellowed, opaque with loss of brightness; rough when probe is gently } \\
\text { run over the surface; generally covered with biofilm. No clinically detectable loss of substance. } \\
\text { Smooth surface: caries lesion typically located close to the gingival margin, arched shape (like a } \\
\text { banana) or rim (proximal surfaces). }\end{array}$ \\
\hline 3 & $\begin{array}{l}\text { Active caries, surface } \\
\text { with discontinuity }\end{array}$ & $\begin{array}{l}\text { The same criterion as score 1, with surface defect (microcavity) located only in enamel. Without } \\
\text { unsupported enamel or softened floor detectable with probe. }\end{array}$ \\
\hline Active caries, cavity & $\begin{array}{l}\text { Cavity in enamel/dentin easily visible to the naked eye; the cavity surface appears to be softened } \\
\text { on gentle probing. There may or may not be pulp involvement. }\end{array}$ \\
\hline 5 & $\begin{array}{l}\text { Inactive caries, intact } \\
\text { surface }\end{array}$ & $\begin{array}{l}\text { The enamel surface is whitened, brown or black. The enamel may be shiny with smooth, hardened } \\
\text { texture when the probe is gently run over the surface. Without clinically detectable loss of sub- } \\
\text { stance. Smooth surface: caries lesion typically located at some distance from the gingival margin. }\end{array}$ \\
\hline 6 & Inactive caries, surface & $\begin{array}{l}\text { The same criterion as score 4, with surface defect (microcavity) located only in enamel. Without } \\
\text { unsupported enamel or softened floor detectable with probe. }\end{array}$ \\
\hline
\end{tabular}

Table 2. Cutoff point values for classification of caries lesions by DIAGNOdent pen, according to values suggested by Lussi et al. [2006]

\begin{tabular}{lll}
\hline $\begin{array}{l}\text { Gold } \\
\text { standard }\end{array}$ & Histological aspect & $\begin{array}{l}\text { DIAGNOdent } \\
\text { pen }\end{array}$ \\
\hline $\mathrm{D}_{0}$ & $\begin{array}{l}\text { no caries } \\
\text { caries extending up to halfway } \\
\mathrm{D}_{1}\end{array}$ & $\begin{array}{l}0-6 \\
\text { through the enamel }\end{array}$ \\
$\mathrm{D}_{2}$ & $\begin{array}{l}\text { caries in the inner half of enamel } \\
\text { caries extending into the dentin }\end{array}$ & $9.1-15$ \\
$\mathrm{D}_{3}, \mathrm{D}_{4}$ & $>15$ \\
\hline
\end{tabular}

then performed directly on the proximal surface, preceded by the calibration steps previously described. All examinations were double-blind examinations.

\section{Validation with $\mu C T$}

After all examinations had been performed, 63 surfaces out of the total sample were used for the study validation by $\mu \mathrm{CT}$, using the SkyScan device (SkyScan 1174, Kontich, Belgium). The specimens were rotated through $360^{\circ}$, at a rotation speed of 1.0 , with a frame average of 2 and randomized movements. A $0.25-\mathrm{mm}$ aluminum filter was used. The teeth were scanned at a power of $50 \mathrm{kV}$ and $800 \mu \mathrm{A}$. Each exam lasted an average of $35 \mathrm{~min}$. The geometrical correction resources of the field of acquisition (flat field) were used. The teeth were three-dimensionally reconstructed using the program NRecon, version 1.6.0.3, applying maximum reduction of ring artifacts and maximum beam hardening correction (100\%). The images, stored in 16-bit TIFF files, were reconstructed and
Table 3. Radiographic and tomographic evaluation, criteria proposed by Kidd et al. [2005] and Mejàre et al. [1999]

\begin{tabular}{ll}
\hline Score & Criterion \\
\hline 0 & Healthy \\
\hline 2 & Demineralization confined to external half of enamel \\
\hline 3 & $\begin{array}{l}\text { Cemineralization invading external half of enamel } \\
\text { junction, without evident propagation in dentin }\end{array}$ \\
\hline 4 & $\begin{array}{l}\text { Caries lesion in dentin; evident propagation in the direc- } \\
\text { tion of the external half of dentin (less than halfway in the } \\
\text { direction of the pulp) }\end{array}$ \\
\hline 5 & $\begin{array}{l}\text { Caries lesion in dentin; obvious propagation in the direc- } \\
\text { tion of the internal half of dentin (more than halfway in } \\
\text { the direction of the pulp) }\end{array}$
\end{tabular}

saved in BMP format with a resolution of $1,024 \times 1,024$ pixels. The reconstructed images were evaluated and classified with regard to depth of lesion by means of visualizing the sagittal cut, following the same clinical and radiographic evaluation scores as specified in tables 1 and 2. The program Data Viewer was used in the classification of the images by means of visualizing the reconstructions in black and white and in color. Table 4 shows some of the cuts obtained from the samples in the present study, exemplifying each of the previously described scores and the correlation with the clinical scores obtained using the Nyvad index, BW and DIAGNOdent 
Table 4. Cuts obtained by $\mu$ CT representing each of the scores described in tables 1-3

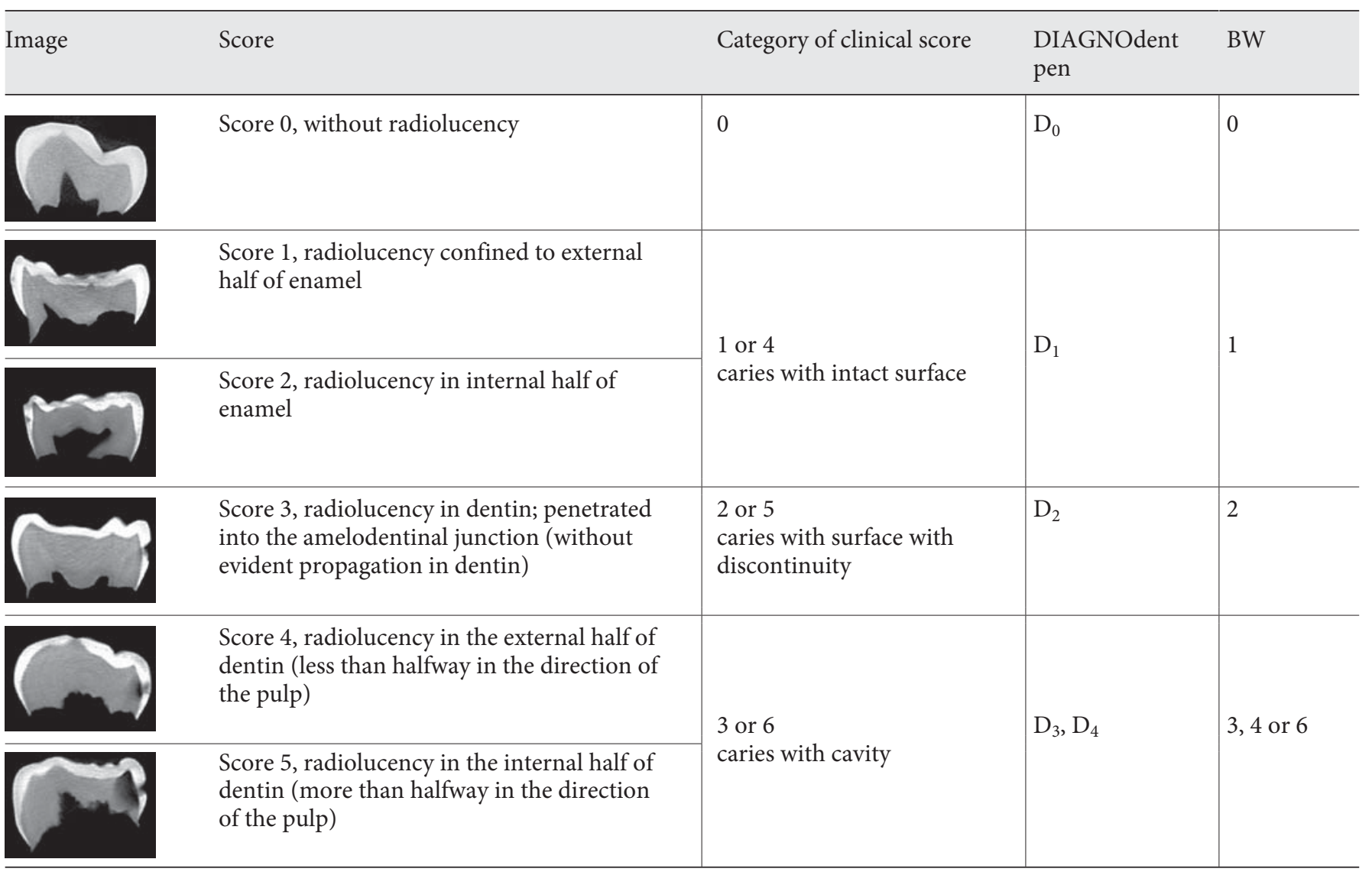

pen readings. For each sample and among the cuts obtained of each surface, the image with the deepest lesion was considered for determination of the score.

The degree of correction among the results obtained was evaluated according to nonparametric statistical tools by means of the Spearman (Spearman Rank-Order) tests. Principal component analysis (PCA) and cluster analysis were used to group elements of the sample and situate observations in homogeneous groups, these groups being heterogeneous among them. For statistical analysis, the Statistics 8.0 of the StatSoft program was used. All of the analyses were performed adopting a level of significance of $\alpha=0.05$.

In addition, sensitivity, specificity and accuracy 95\% confidence intervals were calculated using an approach appropriate for clustered samples (http://vassarstats.net) comparing the results obtained by the exams to the results of $\mu \mathrm{CT}$. The calculations were made at three thresholds (D1, D2 and D3). D1: $\mathrm{D}_{0}=$ health, $\mathrm{D}_{1}-\mathrm{D}_{4}$ = disease; D2: $\mathrm{D}_{0}, \mathrm{D}_{1}=$ health, $\mathrm{D}_{2}-\mathrm{D}_{4}=$ disease; D3: $\mathrm{D}_{0}-\mathrm{D}_{2}=$ health, $\mathrm{D}_{3}, \mathrm{D}_{4}=$ disease. Accuracy was calculated by means of sensitivity and specificity at all thresholds (MedCalc for Windows, version 9.3.0.0, Mariakerke, Belgium). Table 4 shows the categorizations established for each test in order to perform sensitivity and specificity analysis.

Contact Points Influence Approximal Caries Detection

\section{Results}

The sample composition consisted of 74 first primary molars and 63 second primary molars. Table 5 presents the distribution of score levels from EX1, EX2, LF1, LF2, BW and $\mu \mathrm{CT}$.

Figure 2 shows the PCA and cluster analysis of the data obtained. It can be observed, according to PCA (fig. 2a), based on a correlation matrix (about $70 \%$ of variability explained by two main factors, 1 and 2, presented in the axis of the following picture), that there is a stronger correlation between EX2, LF3, $\mu$ CT, BW and LF2. Variables were evaluated adopting the patients as the grouping variable. All variables are close to the unit circle, showing good model adequacy. A cluster analysis was also performed based on the Single Linkage Grouping Method and Euclidean distances. Again, similarity among $\mu \mathrm{CT}$, BW, EX1 and EX2 is observed (fig. 2b).

In table 6, it may be observed that the ability of the correct detection of caries lesions (sensitivity) has increased 


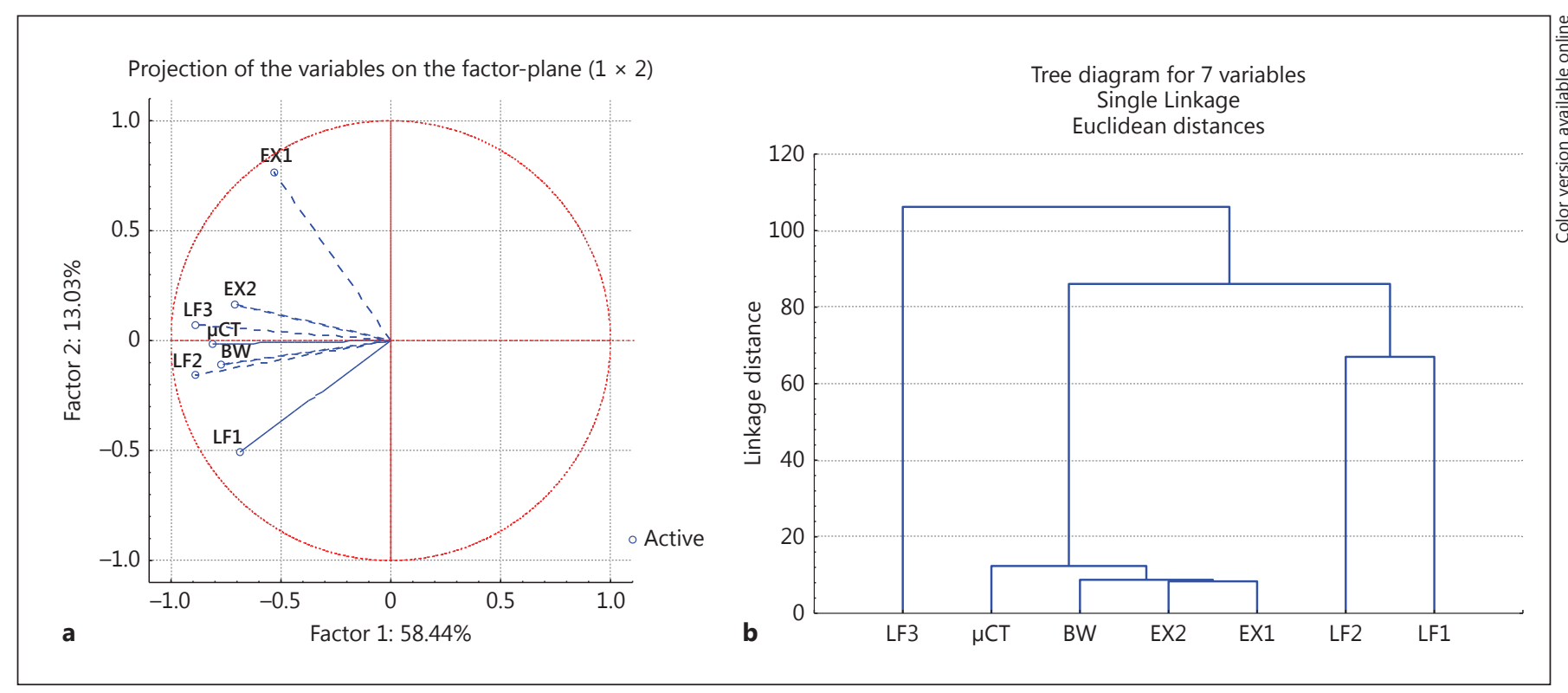

Fig. 2. Multivariate statistical analysis graphics. a PCA to convert a set of observations of possibly correlated variables into a set of values of linearly uncorrelated variables. b Cluster analysis to clas- sify objects into relatively homogeneous groups based on the set of variables analyzed.

Table 5. Frequency distribution of the sample, divided into scores used in DIAGNOdent pen (LF1, LF2), visual-tactile examination (EX1, EX2), BW and $\mu \mathrm{CT}$

\begin{tabular}{|c|c|c|c|c|c|c|c|c|c|c|}
\hline \multirow[t]{2}{*}{ Scores } & \multirow{2}{*}{$\begin{array}{l}\text { LF1 } \\
\text { frequency } \\
\left(\mathrm{F}_{\mathrm{i}}\right)\end{array}$} & \multirow{2}{*}{$\begin{array}{l}\mathrm{LF} 2 \\
\text { percentage } \\
\left(\mathrm{F}_{\mathrm{R}} \%\right)\end{array}$} & \multicolumn{2}{|l|}{ EX1 } & \multicolumn{2}{|l|}{$\mathrm{EX} 2$} & \multicolumn{2}{|l|}{ BW } & \multicolumn{2}{|l|}{$\mu \mathrm{CT}$} \\
\hline & & & $\begin{array}{l}\text { frequency } \\
\left(\mathrm{F}_{\mathrm{i}}\right)\end{array}$ & $\begin{array}{l}\text { percentage } \\
\left(\mathrm{F}_{\mathrm{R}} \%\right)\end{array}$ & $\begin{array}{l}\text { frequency } \\
\left(\mathrm{F}_{\mathrm{i}}\right)\end{array}$ & $\begin{array}{l}\text { percentage } \\
\left(\mathrm{F}_{\mathrm{R}} \%\right)\end{array}$ & $\begin{array}{l}\text { frequency } \\
\left(\mathrm{F}_{\mathrm{i}}\right)\end{array}$ & $\begin{array}{l}\text { percentage } \\
\left(\mathrm{F}_{\mathrm{R}} \%\right)\end{array}$ & $\begin{array}{l}\text { frequency } \\
\left(F_{i}\right)\end{array}$ & $\begin{array}{l}\text { percentage } \\
\left(\mathrm{F}_{\mathrm{R}} \%\right)\end{array}$ \\
\hline $\mathrm{D}_{0}$ & 107 & 51.2 & & & & & & & & \\
\hline $\mathrm{D}_{1}$ & 28 & 13.4 & & & & & & & & \\
\hline $\mathrm{D}_{2}$ & 22 & 10.5 & & & & & & & & \\
\hline $\mathrm{D}_{3}$ & 52 & 24.9 & & & & & & & & \\
\hline 0 & & & 166 & 79.4 & 131 & 62.7 & 182 & 86.9 & 25 & 39.7 \\
\hline 1 & & & 29 & 13.9 & 50 & 23.9 & 3 & 1.4 & 9 & 14.3 \\
\hline 2 & & & 3 & 1.4 & 11 & 5.3 & 3 & 1.4 & 11 & 17.5 \\
\hline 3 & & & 4 & 1.9 & 8 & 3.8 & 5 & 2.4 & 4 & 6.3 \\
\hline 4 & & & 5 & 2.4 & 7 & 3.3 & 7 & 3.3 & 9 & 14.3 \\
\hline 5 & & & 2 & 1.0 & 2 & 1.0 & 9 & 4.6 & 5 & 7.9 \\
\hline Total & 209 & 100 & 209 & 100 & 209 & 100 & 209 & 100 & 63 & 100 \\
\hline
\end{tabular}

in both visual-tactile and DIAGNOdent pen examinations after separation of interproximal contacts (EX2 and LF2, respectively), at all thresholds. When evaluating the ability to correctly detect sound surfaces (specificity), the interproximal contact influenced the DIAGNOdent pen examination results; specificity was increased, mainly at the D1 threshold (LF1 and LF2).
Accuracy results also are displayed in table 6, which shows that the visual-tactile and DIAGNOdent pen examinations where improved after the use of orthodontic separating elastics. The higher difference of scores for both examinations was observed on the threshold D1 (for EX1 and EX2, and for LF1 and LF2). 
Table 6. Values of sensitivity, specificity and accuracy of the examination methods used, compared with the results of $\mu \mathrm{CT}$

\begin{tabular}{cllllll}
\hline & EX1 & EX2 & BW & LF1 & LF2 & LF3 \\
\hline Sensitivity & & & & & & \\
D1 & $0.37(0.22-0.54)$ & $0.60(0.43-0.75)$ & $0.27(0.14-0.46)$ & $0.47(0.30-0.64)$ & $0.63(0.44-0.78)$ & $0.68(0.57-0.86)$ \\
D2 & - & - & $0.23(0.11-0.35)$ & $0.38(0.20-0.53)$ & $0.63(0.46-0.70)$ & $0.69(0.41-0.73)$ \\
D3 & $0.05(0.43-0.75)$ & $0.11(0.05-0.43)$ & $0.37(0.17-0.67)$ & $0.31(0.13-0.43)$ & $0.53(0.25-0.69)$ & $0.78(0.27-0.59)$ \\
Specificity & & & & & & \\
D1 & $1.00(0.83-1.00)$ & $0.92(0.72-0.98)$ & $1.00(0.82-1.00)$ & $0.68(0.46-0.84)$ & $0.92(0.72-0.98)$ & $0.76(0.70-0.86)$ \\
D2 & - & - & $1.00(0.87-1.00)$ & $0.85(0.58-0.92)$ & $0.88(0.71-0.98)$ & $0.85(0.67-0.97)$ \\
D3 & $1.00(0.91-1.00)$ & $1.00(0.91-1.00)$ & $1.00(0.89-1.00)$ & $0.84(0.66-0.96)$ & $0.91(0.76-0.99)$ & $0.91(0.72-0.96)$ \\
Accuracy & & & & & & \\
D1 & $0.62(0.50-0.74)$ & $0.73(0.62-0.84)$ & $0.57(0.44-0.70)$ & $0.56(0.43-0.69)$ & $0.75(0.64-0.86)$ & $0.71(0.60-0.82)$ \\
D2 & - & - & $0.64(0.53-0.75)$ & $0.54(0.42-0.67)$ & $0.77(0.68-0.81)$ & $0.78(0.68-0.88)$ \\
D3 & $0.71(0.68-0.88)$ & $0.75(0.66-0.85)$ & $0.82(0.74-0.94)$ & $0.69(0.58-0.64)$ & $0.80(0.68-0.92)$ & $0.87(0.76-0.98)$ \\
\hline
\end{tabular}

D1: $\mathrm{D}_{0}=$ health; $\mathrm{D}_{1}-\mathrm{D}_{3}=$ disease. $\mathrm{D} 2: \mathrm{D}_{0}, \mathrm{D}_{1}=$ health; $\mathrm{D}_{2}, \mathrm{D}_{3}=$ disease. $\mathrm{D} 3: \mathrm{D}_{0}-\mathrm{D}_{2}=$ health; $\mathrm{D}_{3}=$ disease.

Values in parentheses are $95 \%$ confidence intervals.

Table 7. Statistical correlation of the data by the Spearman nonparametric method for $\alpha=0.05$

\begin{tabular}{llllllll}
\hline Variables & LF1 & LF2 & LF3 & EX1 & EX2 & BW & $\mu$ CT \\
\hline LF1 & - & 0.33 & n.s. & 0.14 & 0.24 & 0.18 & n.s. \\
LF2 & 0.33 & - & 0.39 & 0.35 & 0.41 & 0.33 & 0.35 \\
LF3 & n.s. & 0.39 & - & n.s. & 0.39 & 0.30 & n.s. \\
EX1 & 0.14 & 0.35 & n.s. & - & 0.57 & 0.34 & 0.33 \\
EX2 & 0.24 & 0.41 & 0.39 & 0.57 & - & 0.43 & 0.35 \\
BW & 0.18 & 0.33 & 0.30 & 0.34 & 0.43 & - & n.s. \\
$\mu C T$ & n.s. & 0.35 & n.s. & 0.33 & 0.35 & n.s. & - \\
\hline
\end{tabular}

n.s. $=$ Not significant.

The BW method showed the lowest values of sensitivity and the highest values of specificity at all thresholds. Accuracy was higher at D3 level than with the other methods tested.

Analysis of the correlation between the methods (table 7), among those considered significant at level $\alpha=0.05$ by means of the Spearman nonparametric test, revealed that the higher correlation score was found between scores EX1 and EX2. When comparing LF1 and LF2, this correlation has improved when there was no interproximal contact (LF2). Besides, the use of orthodontic separating elastics improved the correlation between DIAGNOdent pen and $\mu \mathrm{CT}$ results, once LF1 was not statistically significant and LF2 was 0.35 . In relation to BW, it was observed that the higher score was found between correlations with EX2.

Contact Points Influence Approximal Caries Detection

\section{Discussion}

The dynamic nature of the caries process and the contemporary change in the caries progression pattern have stimulated the search for knowledge on caries and the development of technology, aiming to recognize carious lesions on tooth surfaces at much earlier stages, before they reach the stage of cavitation. It would be appreciated to develop the ability to clinically differentiate the detected lesions according to their stage of progression, once it would allow dental professionals to interfere with the progression and to control it, particularly in noncavitated caries lesions. This is justified because these early lesions require nonoperative treatment, active progressing lesions could be turned into arrested, inactive lesions, before they reach cavitation stage [Nyvad et al., 2003]. In children, some aspects also support the relevance of diagnosing early stages of caries lesions, such as the discomfort of some operative procedures, particularly in small children, rapid progression to advanced stages of the disease in primary teeth and the higher cost of operative treatment.

The sensitivity and accuracy were improved in all examinations after approximal contact separation, at all three thresholds. It is particularly important at D1 threshold, which differentiates incipient caries lesions from sound surfaces. The use of orthodontic separating elastics placed between suspicious selected surfaces could represent a useful tool for caries diagnosis in the presence of clinical signs, i.e. shadow or opacity in the marginal ridge or a kidney-shape lesion close to the gingival margin in 
the smooth surface. In these cases, tooth separation could allow the detection of cavitation, which is hard to manage, since initial lesions might be reversible by themselves after proper biofilm disorganization or fluoride application. In this way, temporary tooth separation may offer the clinician the possibility of determining whether the lesion is cavitated or noncavitated with some degree of accuracy [Hintze et al., 1999] and this technique may be suitable in low-caries, highly motivated individuals.

In relation to specificity, the ability of detecting sound approximal surfaces by visual-tactile examination was not improved by contact separation. On the other hand, approximal contact separation improved specificity scores from DIAGNOdent pen examination, which indicates that the access of laser light to caries lesions in this region still needs to be improved in order to minimize false-positive diagnoses. The only in vivo study conducted up to the writing of this article [Novaes et al., 2009] did not evaluate the influence of contact on the results of the device. From the results of the present study, combined with the clinical observations obtained throughout the exams, the difficult access of laser light to the lesions can be explained by the close and extensive proximal contacts, a characteristic previously reported for primary teeth [Pitts and Rimmer, 1992], and by the presence of the gingival papilla. Lussi et al. [2006] also considered the interference characteristic of contacts in vivo in the results obtained with the device, suggesting further studies with regard to this difficulty. According to Aljehani et al. [2007], potential sources of error in the DIAGNOdent readouts must be considered in the clinic, since the variables cannot be controlled in the same way as they can in studies in vitro.

The BW exam, which also presented high specificity, obtained low sensitivity, especially at D1 and D2 (0.27 and 0.23 ), a result in agreement with the findings of Silva Neto et al. [2008]. Compared with the visual-tactile exam, the radiographic exam presented higher sensitivity at D3, therefore, showing a better capacity to detect lesions in dentin than the visual exam. Based on this characteristic, combined with the accessibility and facility of the technique, the radiograph has been used as a complementary method, improving the estimate of the depth of caries lesions. When compared with the other exams evaluated, however, it demonstrated a low correlation with $\mu \mathrm{CT}$, an indication of its limitation.

In the present study, the visual-tactile scores, before and after tooth separation (EX1 and EX2, respectively), reached higher correlation values (although these values were not statistically significant), and the scores between EX1, EX2 and $\mu$ CT were almost the same. The Nyvad sys- tem for caries diagnosis defines activity for both cavitated and noncavitated lesions. These results could be explained by the fact that this examination was performed by an experienced examiner. This evidence was emphasized by a previous study, which showed that training might be an important tool in improving the performance of professionals [Séllos and Soviero, 2011]. On the other hand, when comparing LF1 and LF2, this correlation was improved when there was no interproximal contact (LF2). Also, the direct examination after using orthodontic separating elastics improved the correlation between DIAGNOdent pen and $\mu \mathrm{CT}$ results, once LF1 was statistically not significant and LF2 was 0.35 . Nevertheless, it should be mentioned that the table of cutoff points used in this study was taken from an in vitro study with permanent teeth [Lussi et al., 2006]. Considering that the table of cutoff points contributes directly to the results, that the tables obtained from DIAGNOdent cannot be inferred for the DIAGNOdent pen [Kühnisch et al., 2007b] and in view of the positive correlation obtained for the DIAGNOdent pen-categorized values it is recommended that for the determination of new cutoff points, in vivo research should be conducted with histological validation using the DIAGNOdent pen in primary teeth.

In relation to BW, it was observed that the highest correlation was found with EX2 $(r=0.43)$. The correlation of BW and $\mu \mathrm{CT}$ was not statistically significant. In other words, DIAGNOdent pen and visual-tactile criteria had their correlation scores improved when there was not an approximal contact point.

Considering the multivariate statistical analysis, PCA and cluster analysis were performed to evaluate the data aiming at its reduction, elimination of overlapping and a more representative selection of data from linear combinations of the original variables. It could be observed that the correlations were in accordance with Spearman's correlation test.

The use of $\mu \mathrm{CT}$ as the gold standard is an option that has recently been investigated. Traditionally, the stereomicroscope and the optical microscope have been the histological analyses used as the gold standard for the validation of caries diagnosis studies; they are based on visual inspection of changes in the appearance of dental tissues. However, both of the methods cause destruction of the tooth and may make it difficult to examine the extension of the caries lesion [Huysmans and Longbottom, 2004]. Analysis by $\mu \mathrm{CT}$ has the advantage of being a nondestructive method, which allows visualization of dental structures and caries lesions in three dimensions [Swain and Xue, 2009]. Soviero et al. [2012] evaluated the effective- 
ness of $\mu \mathrm{CT}$ in the detection and evaluation of caries lesions on the proximal surfaces of primary teeth and found that this method has high sensitivity in the detection of initial lesions in enamel and in the differentiation of lesions in enamel and dentin, and could thus be used as the gold standard in caries lesion detection on the proximal surfaces of primary molars.

The in vitro and in vivo conditions were analyzed in this study without the presence of the point of contact. In other words, the readouts were taken directly on the proximal surface, in contrast to the other in vitro studies cited, which had the object of simulating the situation of proximal contact. In this analysis, the results of LF2 (in vivo) and LF3 (in vitro) were compared. In the evaluation of dentin lesions, the LF3 exam obtained slightly higher sensitivity values (0.78) than the other exams. A possible explanation could be the fact that the extraoral evaluations were made with greater proximity of the tip of the device to the surface examined (direct access of laser light), while the intraoral evaluations were made through the interdental space obtained after separation with orthodontic elastic, which in some cases did not allow direct contact of the tip with the tooth surface. As there are no similar studies for the evaluation of this variable, we suggest that further studies be conducted with these considerations in mind.

In a longitudinal study on dental students using temporary tooth separation, approximately $20 \%$ of approximal lesions with an intact surface, which were in the outer dentin radiographically, developed cavitation during the first 1.5-year period, indicating that not all dentinal lesions may be arrested, even among motivated individuals [Hintze et al., 1999]. Temporary tooth separation is not an applicable tool in all patients or clinical trials, and monitoring lesion behavior may still rely on radiography, with its inaccuracies and observer variations taken into account [Wenzel, 2004]. It should be pointed out that we believe that the minor mobility observed in the first appointment did not influence the scores obtained from the examinations. In few cases, in the second appointment, due to the elastic separation applied, the mobility was increased, but still could be classified as score 1 of the Miller classification. These observations must be taken into consideration due to the design of the present study, where authors would like to perform in vitro analysis of DIAGNOdent pen and $\mu \mathrm{CT}$. But, in clinical practice, the use of approximal contact separation should be considered as an important tool, mainly to be used in specific sites where the clinician suspects the presence of initial caries lesions.

It should also be emphasized that the differential in this study is that the use of exfoliated teeth made it possible to

Contact Points Influence Approximal

Caries Detection compare different diagnostic tools using the $\mu \mathrm{CT}$ as the gold standard. The only in vivo study in primary teeth that compared diagnostic methods (visual examination, BW and DIAGNOdent pen) used the dental examination as a reference standard [Novaes et al., 2012]. In other words, this is the first in vivo and in vitro study that compares the influence of temporary tooth separation on the visual examination, BW and DIAGNOdent pen, using $\mu \mathrm{CT}$ as the gold standard. Another important contribution of this study is in relation to the methodology used, where the clinical assays in primary teeth made possible follow-up until its exfoliation, enabling the same tooth to be observed and compared by gold standard methods.

In view of the foregoing, the conclusions of the present study are: visual-tactile exam, using the Nyvad criteria, presented better results than the DIAGNOdent pen and BW in the diagnosis of sound approximal surfaces and approximal caries lesions without tooth separation in primary molars. However, the performance of the visualtactile exam and the DIAGNOdent pen was highly influenced by approximal contact point, mainly in the detection of noncavitated caries lesions. The use of orthodontic separating elastics can improve the diagnosis of noncavitated lesions and should be used as a complementary tool by the clinician, specially when initial caries lesions are suspected in approximal surfaces in primary molars.

\section{Acknowledgments}

The authors would like to thank FAPERJ (Fundação de Amparo à Pesquisa do Rio de Janeiro, Proc. E.26/110.499/2010) and PROPPi/UFF (Pró-Reitoria de Pesquisa, Pós-graduação e Inovação/Universidade Federal Fluminense) for the financial support received. The funders had no role in study design, data collection and analysis, decision to publish, or preparation of the manuscript.

\section{Author Contributions}

Conceived and designed the experiments: A.A.R., J.A.R., A.B.V. Calibration of DIAGNOdent pen exams: J.A.R., A.L. Performed the visual-tactile examination: A.A.R. Performed the DIAGNOdent pen examinations: F.P. Performed the bitewing examinations: P.R.A.O. Performed the computed microtomography analysis: J.T.A., H.D.L.A. Analyzed the data: A.H.M. Wrote the paper: A.A.R., F.P., J.A.R., A.L., A.H.M., A.B.V.

\section{Disclosure Statement}

The authors declare that there are no potential conflicts of interest. 


\section{References}

Aljehani A, Yang L, Shi X: In vitro quantification of smooth surface caries with DIAGNOdent and the DIAGNOdent pen. Acta Odontol Scand 2007;65:60-63.

-Braga MM, Morais CC, Nakama RC, Leamari VM, Siqueira WL, Mendes FM: In vitro performance of methods of approximal caries detection in primary molars. Oral Surg Oral Med Oral Pathol Oral Radiol Endod 2009; 108:e35-e41.

Ekstrand K: Diagnóstico da cárie; in Buischi YP (ed): Promoção de Saúde Bucal na Clínica Odontológica. Porto Alegre, Artes Médicas, 2000, pp 127-148.

- Francescut P, Zimmerli B, Lussi A: Influence of different storage methods on laser fluorescence values: a two-year study. Caries Res 2006;40:181-185.

Hala LA, Mello JB, Carvalho PL: Evaluation of the effectiveness of clinical and radiographic analysis for the diagnosis of proximal caries for different clinical experience levels: comparing lesion depth through histological analysis. Bras J Oral Sci 2006;5:1012-1017.

-Hintze H, Wenzel A: Clinically undetected dental caries assessed by bitewing screening in children with little caries experience. Dentomaxillofac Radiol 1994;23:19-23.

-Hintze H, Wenzel A, Danielsen B: Behaviour of approximal carious lesions assessed by clinical examination after tooth separation and radiography: a 2.5-year longitudinal study in young adults. Caries Res 1999;33:415-422.

-Huysmans MC, Longbottom C: The challenges of validating diagnostic methods and selecting appropriate gold standards. J Dent Res 2004; 83:C48-C52.

Kidd EAM, Mejàre I, Nyvad B: Clinical and radiographic diagnosis; in Fejerskov O, Kidd E (eds): Cárie dentária - A doença e seu tratamento clínico. São Paulo, Santos Editora 2005, pp 111-128.

-Kühnisch J, Bücher K, Henschel V, Hickel R: Reproducibility of DIAGNOdent 2095 and DIAGNOdent Pen measurements: results from an in vitro study on occlusal sites. Eur J Oral Sci 2007a;115:206-211.
Kühnisch J, Bücher K, Hickel R: The intra/interexaminer reproducibility of the new DIAGNOdent Pen on occlusal sites. J Dent 2007b; 35:509-512.

Lussi A, Hack A, Hug I, Heckenberger H, Megert B, Stich H: Detection of approximal caries with a new laser fluorescence device. Caries Res 2006;40:97-103.

Lussi A, Hellwig E: Performance of a new laser fluorescence device for the detection of occlusal caries in vitro. J Dent 2006;34:467-471.

Mejàre I, Källestål C, Stenlund H: Incidence and progression of approximal caries from 11 to 22 years of age in Sweden: a prospective radiographic study. Caries Res 1999;33:93-100.

Miller SC: Textbook of Periodontia, ed 1. Philadelphia, Blakiston, 1938.

Mortimer KV: The relationship of deciduous enamel structure to dental disease. Caries Res 1970;4:206-223.

Murray JJ, Majid ZA: The prevalence and progression of approximal caries in the deciduous dentition in British children. Br Dent J 1978;145:161-164.

Novaes TF, Matos R, Braga MM, Imparato JC, Raggio DP, Mendes FM: Performance of a pen-type laser fluorescence device and conventional methods in detecting approximal caries lesions in primary teeth - in vivo study. Caries Res 2009;43:36-42.

Novaes TF, Matos R, Celiberti P, Braga MM, Mendes FM: The influence of interdental spacing on the detection of proximal caries lesions in primary teeth. Braz Oral Res 2012;26: 293-299.

Novaes TF, Matos R, Raggio DP, Imparato JCP, Braga MM, Mendes FM: Influence of the discomfort reported by children on the performance of approximal caries detection methods. Caries Res 2010;44:465-471.

Nyvad B, Machiulskiene V, Baelum V: Reliability of a new caries diagnostic system differentiating between active and inactive caries lesions. Caries Res 1999;33:252-260.

Nyvad B, Machiulskiene V, Baelum V: Construct and predictive validity of clinical caries diagnostic criteria assessing lesion activity. J Dent Res 2003;82:117-122.
Nyvad B, Machiulskiene V, Fejerskov O, Baelum $\mathrm{V}$ : Diagnosing dental caries in populations with different levels of dental fluorosis. Eur J Oral Sci 2009; 177:161-168.

Pitts NB, Rimmer PA: An in vivo comparison of radiographic and directly assessed clinical caries status of posterior approximal surfaces in primary and permanent teeth. Caries Res 1992;26:146-152.

Ricketts DN, Whaites EJ, Kidd EA, Brown JE, Wilson RF: An evaluation of the diagnostic yield from bitewing radiographs of small approximal and occlusal carious lesions in a low prevalence sample in vitro using different film types and speeds. Br Dent J 1997;182:51-58.

Rodrigues JA, Hug I, Diniz MB, Lussi A: Performance of fluorescence methods, radiographic examination and ICDAS II on occlusal surfaces in vitro. Caries Res 2008;42:297-304.

-Sanden E, Koob A, Hassfeld S, Staehle HJ, Eickholz P: Reliability of digital radiography of interproximal dental caries. Am J Dent 2003; 16:170-176.

Séllos MC, Soviero VM: Reliability of the Nyvad criteria for caries assessment in primary teeth. Eur J Oral Sci 2011;119:225-231.

Silva Neto JM, Santos RL, Sampaio MCC, Sampaio FC, Passos IA: Radiographic diagnosis of incipient proximal caries: an ex-vivo study. Braz Dent J 2008;19:97-102.

Soviero VM, Leal SC, Silva RC, Azevedo RB: Validity of MicroCT for in vitro detection of proximal carious lesions in primary molars. J Dent 2012;40:35-40.

Swain MV, Xue J: State of the art of micro-CT applications in dental research. Int J Oral Sci 2009;1:177-188.

Wenzel A: Digital imaging for dental caries. Dent Clin North Am 2000;44:319-338.

Wenzel A: Bitewing and digital bitewing radiography for detection of caries lesions (review). J Dent Res 2004;83:C72-C75.

Wilson PR, Beynon AD: Mineralization differences between human deciduous and permanent enamel measured by quantitative microradiography. Arch Oral Biol 1989;34:85-88. 


\section{Erratum}

In the article by Ribeiro AA, Purger F, Rodrigues JA, Oliveira PRA, Lussi A, Monteiro AH, Alves HDL, Assis JT and Vasconcellos AB, entitled 'Influence of contact points on the performance of caries detection methods in approximal surfaces of primary molars: an in vivo study' [Caries Res 2015;49:99-108], there is a change in table 1, p. 102: for score 6, the category should be changed to 'Inactive caries, cavity'. 